\title{
MÉTODO DE ANÁLISE HIERÁRQUICA (AHP) APLICADO A INUNDAÇÃO URBANA APÓS EVENTO DE CHUVA CONCENTRADO
}

\author{
ANDRE LUIZ NASCENTES COELHO ${ }^{1}$ \\ ${ }^{1}$ Universidade Federal do Espírito Santo \\ Av. Fernando Ferrari, 514 - Goiabeiras, Vitória - ES, 29075-910, Brasil. \\ alnc.ufes@gmail.com
}

\section{RESUMO}

O objetivo principal deste artigo foi espacializar as manchas de inundação do Município de Vitória no Estado do Espírito Santo, Brasil, empregando o Processo de Análise Hierárquica (AHP), validando o mapeamento em registros documentais, campanhas de campo e em um evento de maior precipitação concentrado dos últimos quarenta e cinco anos. O resultado permitiu delimitar e calcular as áreas inundáveis em graus de susceptibilidades comprovando sua eficiência através de documentos e informações. Tal metodologia possibilita a avaliação de outras áreas de municípios e regiões com características semelhantes, constituindo-se numa importante informação no auxílio da gestão territorial, como a implantação ou revisão de Plano de Drenagem Urbana e Plano Diretor Municipal.

Palavras-chave: AHP; Geomorfologia Fluvial Urbana; SIG; Ordenamento Territorial e Ambiental.

\section{ANALYTIC HIERARCHY PROCESS (AHP) APPLIED TO URBAN FLOOD AFTER CONCENTRATED RAIN EVENT}

\section{ABSTRACT}

The main objective of this article was to spatialize the flood spots of the Municipality of Vitória in the State of Espírito Santo, Brazil, from the Analysis Hierarchical Process (AHP), validating the mapping in documents, photographic records, and field work in a larger event concentrated rainfall of the last 45 years. The result allowed defining and calculating the flood areas in degrees of susceptibility and proving their efficiency in data and information. Such methodology allows the evaluation of other areas of municipalities and regions with similar characteristics, constituting important information in aid of territorial management, for example, the implementation or revision of Urban Drainage Plan and Municipal Director Plan.

Keywords: AHP; Urban Fluvial Geomorphology; GIS; Regional Planning and Environmental. 
Coelho, A. L. N. (2017): "Método de análise hierárquica (AHP) aplicado a inundação urbana após evento de chuva concentrado”, GeoFocus (Artículos), no 20, p. 183-199. ISSN: 1578-5157 http://dx.doi.org/10.21138/GF.565

\section{Introdução}

Os eventos de inundações, sobretudo no ambiente urbano, evidenciam um dos grandes problemas enfrentados no mundo contemporâneo e, conforme EM-DAT (2015) e Sausen e Narvaes (2015) são responsáveis por aproximadamente $55 \%$ de todos os desastres naturais registrados e cerca $72,5 \%$ das perdas econômicas. De acordo com Castro (2005), a inundação é o transbordamento de água da calha normal de rios, mares e lagoas ou acumulação de água por drenagem ineficiente em locais não habitualmente submersos.

Os ambientes urbanos, em sua maioria, são constituídos por uma diversidade de superfícies impermeáveis como telhados, concreto, asfalto e durante os eventos de precipitação intensos, de curta duração, resulta na aceleração do escoamento superficial provocando o aumento da vazão máxima e redução do tempo de pico, com a quantidade de água que chega simultaneamente aos canais ou córregos, superiores à sua capacidade de drenagem, culminando na inundação (Cunha, 2012; Chin, 2006). Este evento, muitas vezes, é agravado nas cidades litorâneas durante o nível de maré alta, dificultando ou impedindo o escoamento das águas pluviais em direção ao mar (Tucci e Bertoni, 2003).

Para Carneiro e Migues (2011); Chin (2006) e Cunha (2012 e 2003), as inundações urbanas são decorrentes de uma série de processos materializados ao longo do tempo, notadamente, para a ampliação de moradias construídas de maneira adensada, da supressão da vegetação, da ocupação de áreas ribeirinhas e planícies de inundação, das modificações e extinção dos sistemas de drenagem. Já para Sausen e Narvaes (op cit.); Gregory (2006) e Tucci (2009) o transbordamento das águas no ambiente urbano depende do grau de ocupação pela população, da frequência com a qual elas ocorrem, das práticas inadequadas de uso e cobertura da terra, da sedimentação dos leitos e obstrução ou deficiência de escoamento de canais fluviais.

Nesse contexto, a identificação das áreas potencialmente inundáveis em eventos de temporais está, normalmente, relacionada a fatores importantes como topografia do sítio, modelo de uso da terra, grau superfície impermeabilizada, intensidade e duração das precipitações. Trata-se de um processo dinâmico e complexo tanto no contexto socioambiental quanto temporal. Para tanto, pode-se através a aplicação de modelos em sistemas de informações geográficas (SIGs) avaliar uma determinada área, desde alguns metros, até centenas de quilômetros, proporcionando diversos tipos de análises no âmbito dos estudos geoambientais (Sausen e Narvaes, 2015 e Jensen, 2009).

Diante do exposto, o objetivo principal deste artigo foi espacializar e avaliar as manchas de inundação dos bairros do Município de Vitória-ES com o emprego de variáveis de pesos ponderados, aplicando o Processo de Análise Hierárquica (AHP) em ambiente SIG integrado com produtos acessíveis e técnicas de Sensoriamento Remoto, validando o mapa em registros documentais, campanhas de campo e, em um evento de maior precipitação concentrado.

Como objetivo específico, demonstrar as principais etapas do método de Processo Analítico Hierárquico (AHP) proposto por Saaty (1977) no auxilio da elaboração de um modelo coerente que aponte os locais susceptíveis a inundação; Verificar, em campo, a viabilidade/eficiência da aplicação do modelo gerado; Calcular as áreas e percentuais de inundação por bairros; Difundir o uso de geotecnologias na ciência geográfica e áreas afins. Destaca-se que este trabalho constitui-se 
Coelho, A. L. N. (2017): "Método de análise hierárquica (AHP) aplicado a inundação urbana após evento de chuva concentrado", GeoFocus (Artículos), no 20, p. 183-199. ISSN: 1578-5157 http://dx.doi.org/10.21138/GF.565

numa aproximação indireta ao fenômeno estudado e, portanto, compatível e complementar com estudos de modelagem hidráulica de alta precisão.

\section{Localização e Caracterização da Área de Estudo}

O objeto de estudo, Município de Vitória, Capital do Estado do Espírito Santo é cem por cento urbana, apresentando uma densidade demográfica de $4.208 \mathrm{hab} . / \mathrm{km}^{2}$ e cerca de 363.140 habitantes, de acordo com a estimativa populacional publicada pelo Instituto Brasileiro de Geografia e Estatística em 2017 (Ibge, 2017).

Vitória territorialmente é caracterizada por uma ilha principal e uma porção continental totalizando $86,3 \mathrm{~km}^{2}$ de área, dos quais $41,2 \%$ abrangem os 78 bairros do Município, enquanto os outros 58,8 \% cobrem parte do corpo d água da Baía de Vitória, Canal da Passagem além do Parque Industrial, Aeroporto e o Parque Estadual da Fonte Grande situado em área elevada, não avaliados neste estudo. Dessa área total, $15,7 \mathrm{~km}^{2}$ passou por processos de aterramentos (Figura 1), constituído por materiais hidráulico, sanitário ou inerte, objetivando a implantação e ampliação de usos como avenidas, praças, portos e terrenos para construção, com parte desses, situados abaixo do nível da maré favorecendo a ocorrência das inundações nos eventos concentrados de chuvas (Coelho, 2017).

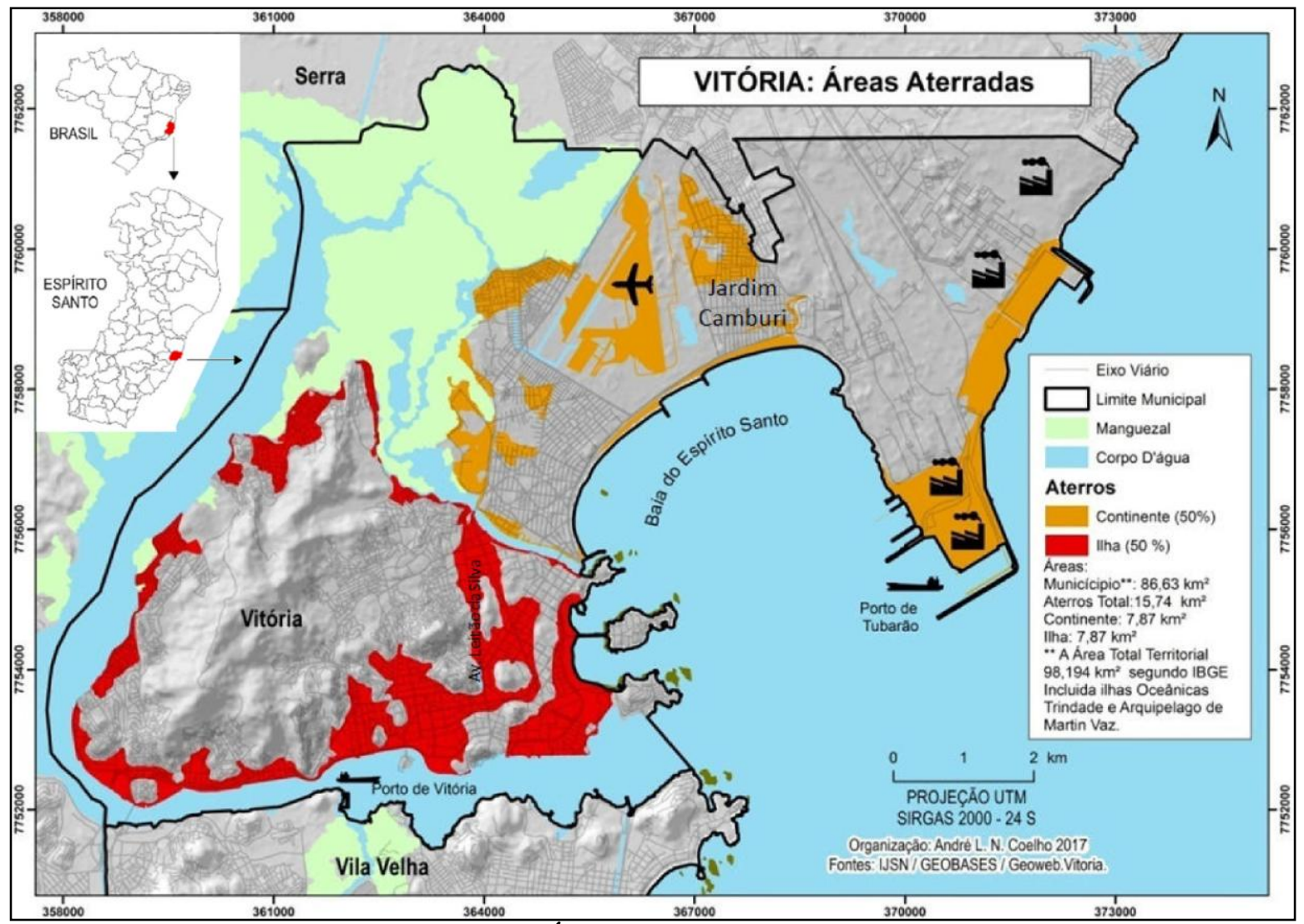

Figura 1 - Áreas Aterradas em Vitória. 
Coelho, A. L. N. (2017): "Método de análise hierárquica (AHP) aplicado a inundação urbana após evento de chuva concentrado", GeoFocus (Artículos), no 20, p. 183-199. ISSN: 1578-5157 http://dx.doi.org/10.21138/GF.565

Os sistemas atmosféricos de escala sinótica que influenciam as condições do tempo no Município estão associados à formação da Zona de Convergência do Atlântico Sul (ZCAS), Frentes Frias (FF) e o Anticiclone ou Alta Subtropical do Atlântico Sul (ASAS), que são importantes mecanismos da dinâmica climática do sudeste brasileiro (Mendonça e Danni-Oliveira, 2007; Varejão-Silva, 2005). No que se refere à pluviometria, os meses de outubro a março correspondem aos mais chuvosos com médias superiores $142 \mathrm{~mm}$, enquanto maio a setembro são caracterizados pela estiagem, havendo o destaque para agosto, o mês mais seco com média de 40mm (Inmet, 2014 e Ibge, 2010).

Parte da cidade de Vitória, assim como outros municípios brasileiros, passou por processo de urbanização resultando na supressão de vegetação, sistemas de drenagens como córregos, ocupação de áreas sob risco de inundações, entre outros. Situação que gera consequências para a população, sobretudo, em períodos de chuvas intensas.

\section{Materiais e Métodos}

Para que os objetivos propostos nesse artigo fossem alcançados, o mesmo foi dividido em duas principais etapas, iniciando-se, com a aquisição de referencial bibliográfico e de documentos abordando a temática, tais como livros; artigos; periódicos; Carta Topográfica do Ibge (1980) SF-24-V-B-1 (Vitória); Relatório e mapas do Projeto Radambrasil (1983); Pesquisa da série histórica de precipitações no Instituto Capixaba de Pesquisa, Assistência Técnica e Extensão Rural (Incaper, 2014), Inmet (2014) e Climatempo (2014), além de dados de marés na Diretoria de Hidrografia e Navegação (Dhn/Chm, 2014).

Na segunda etapa, foram adquiridos os Planos de Informações gratuitos conforme Tabela 1. Dados do modelo digital de elevação Aster/Gdem - Advanced Spaceborne Thermal Emission and Reflection Radiometer / Global Digital Elevation Model de resolução espacial 30 x 30 metros (Usgs, 2011). Uso do GPS de navegação em Plataforma Android, com erro médio de 3 metros e Ortofotomosaico do ano de 2014 (Ijsn/Cgeo, 2014), na validação do produto em campo.

Tabela 1. Base de Dados Geográficas / Planos de Informações utilizados

\begin{tabular}{|l|c|c|c|c|}
\hline \multicolumn{1}{|c|}{ Dado } & Tema & Fonte & Ano & $\begin{array}{c}\text { Escala / } \\
\text { Resolução }\end{array}$ \\
\hline Limite Estadual & Unidades de Federação & IBGE & 2015 & $1: 100000$ \\
\hline Limite Municipal & Município & IJSN/CGEO & 2013 & $1: 1000$ \\
\hline Geomorfologia & Massa d'água (extraído) & IJSN/CGEO & 2013 & $1: 100000$ \\
\hline Edificações & Área Construída & PMV/GEOWEB & 2015 & $1: 1000$ \\
\hline Eixo Viário & Eixo de Logradouros & PMV/GEOWEB & 2015 & $1: 1000$ \\
\hline Rocha & Afloramento de Rochas & PMV/GEOWEB & 2015 & $1: 1000$ \\
\hline Limite de Bairro & Bairros & PMV/GEOWEB & 2015 & $1: 1000$ \\
\hline Aster-GDEM & Modelo Digital de Elevação & USGS & 2011 & 30 metros \\
\hline Ortofotomosaico & Imagem & IJSN/CGEO & 2014 & 1 metro \\
\hline
\end{tabular}

Organizado pelo autor. 
Coelho, A. L. N. (2017): "Método de análise hierárquica (AHP) aplicado a inundação urbana após evento de chuva concentrado", GeoFocus (Artículos), no 20, p. 183-199. ISSN: 1578-5157 http://dx.doi.org/10.21138/GF.565

O processamento dos dados vetoriais e matriciais foi realizado no SIG ArcGIS 10.5, iniciando-se com a criação de um projeto e a adição dos Planos de Informações abrangendo a área de estudo e adjacências ajustados, quando necessário, no sistema de projeção UTM, Datum SIRGAS-2000, Zona 24 Sul (Ibge, 2005), com o mapeamento produzido seguindo a padronização cartográfica segundo Menezes e Fernandes (2013) e Slocum et al. (2008).

O processo de criação do modelo, para identificação de manchas de inundação, partiu com o estabelecimento de coeficientes/graus de importância entre 1 a 10, sendo o valor 10 atribuído à altíssima susceptibilidade e definição do tamanho das células de 5 x 5 metros. A variável Taxa de Impermeabilização teve como base os Planos de Informações vetoriais: Edificações (coeficiente = 8), Eixo de Logradouros (coeficiente $=10$ ), Afloramento de Rochas (coeficiente $=3$ ) e Limite Municipal (coeficiente $=1$ ) que foram unidos a partir do comando Union; seguido da dissolução das classes - comando Dissolve; transformação para matriz - comando Polygon to Raster e aplicação dos respectivos coeficientes a partir da reclassificação - comando Reclassify.

A Elevação partiu modelo digital de elevação Aster/Gdem que foi extraído no Limite Municipal e redefinido com o pixel de $5 \mathrm{~m}$ utilizando um método de interpolação - Topo to Raster especificamente projetado para a criação de modelos de elevação digital hidrologicamente corretos (DEMs). Os comandos foram aplicados nessa sequência: Extract by Mask; Contour; Topo to Raster; e Reclassify, empregando as seguintes classes e coeficientes: Elevação -3 a 1 metros (coeficiente =10); Elevação 1 a 2 metros (coeficiente = 8); Elevação 2 a 3 metros (coeficiente $=6$ ); Elevação 3 a 5 metros (coeficiente $=4$ ) e Elevação maior que 5 metros (coeficiente $=1$ ).

A Declividade/Clinografia foi derivada também do dado Aster/Gdem recortado e redefinido com o pixel de $5 \mathrm{~m}$, utilizando as seguintes classes e coeficientes através dos comandos Slope e Reclassify: Declividades entre 0 a $1 \%$ (coeficiente $=10$ ); Declividades 1 a $2 \%$ (coeficiente $=8$ ); Declividades 2 a $3 \%($ coeficiente $=6)$; Declividades 3 a $4 \%($ coeficiente $=4)$ e Declividades $>4 \%$ (coeficiente $=1$ ).

\subsection{Etapas de Aplicação do Modelo AHP.}

O método AHP proposto por Saaty (1977) apresenta um procedimento para modelar uma situação, representando e quantificando as variáveis envolvidas em uma hierarquia, a partir da avaliação de um conjunto de critérios ponderados por preferências (pesos), auxiliando nos processo de tomadas de decisão, sintetizados na Figura 2. 
Coelho, A. L. N. (2017): "Método de análise hierárquica (AHP) aplicado a inundação urbana após evento de chuva concentrado”, GeoFocus (Artículos), $n^{o}$ 20, p. 183-199. ISSN: 1578-5157 http://dx.doi.org/10.21138/GF.565

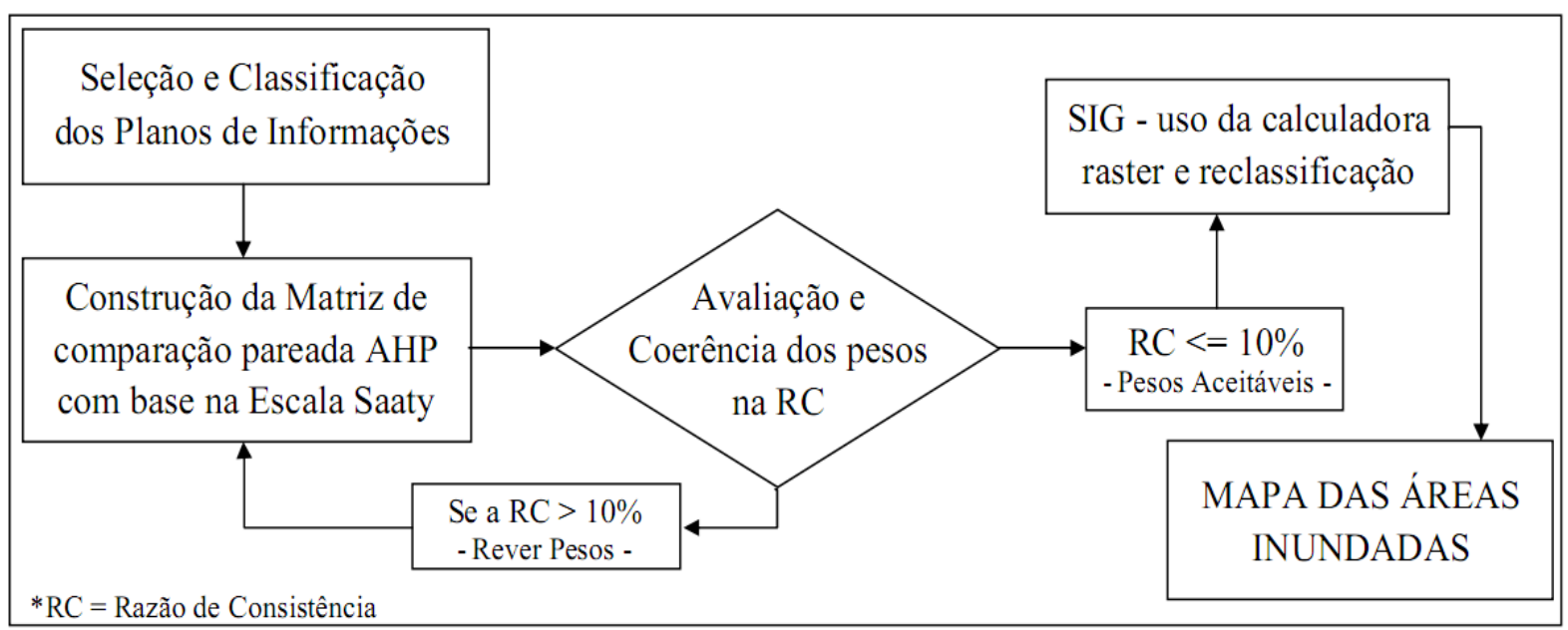

Figura 2. Síntese das principais etapas de aplicação do método AHP.

A aplicação do modelo parte com a definição das variáveis e seus coeficientes atribuindo pesos, com base na Escala de Saaty (Tabela 2), onde o valor 1 equivale ao mínimo, e 9 ao máximo de importância de um fator sobre o outro.

Tabela 2. Escala Saaty com os pesos para correlação pareada entre as variáveis.

\begin{tabular}{|c|l|l|}
\hline $\begin{array}{c}\text { Intensidade de } \\
\text { Importância }\end{array}$ & \multicolumn{1}{|c|}{ Definição } & \multicolumn{1}{c|}{ Explicação } \\
\hline 1 & Igual importância & As duas atividades contribuem igualmente para o objetivo \\
\hline 3 & $\begin{array}{l}\text { Importância pequena de uma } \\
\text { sobre a outra }\end{array}$ & $\begin{array}{l}\text { A experiência e o juízo favorecem uma atividade em relação à } \\
\text { outra }\end{array}$ \\
\hline 5 & $\begin{array}{l}\text { Importância grande ou } \\
\text { essencial }\end{array}$ & $\begin{array}{l}\text { A experiência ou juízo favorece fortemente uma atividade em } \\
\text { relação à outra }\end{array}$ \\
\hline 7 & $\begin{array}{l}\text { Importância muito grande ou } \\
\text { demonstrada }\end{array}$ & $\begin{array}{l}\text { Uma atividade é muito fortemente favorecida em relação à } \\
\text { outra. Pode ser demonstrada na prática. }\end{array}$ \\
\hline $2,4,6$ e 8 & Importância absoluta & $\begin{array}{l}\text { A evidência favorece uma atividade em relação à outra, com o } \\
\text { mais alto grau de segurança. }\end{array}$ \\
\hline Recíprocos acima \\
de 0
\end{tabular}

Fonte: Adaptado de Saaty (1977). 
Coelho, A. L. N. (2017): "Método de análise hierárquica (AHP) aplicado a inundação urbana após evento de chuva concentrado", GeoFocus (Artículos), no 20, p. 183-199. ISSN: 1578-5157 http://dx.doi.org/10.21138/GF.565

Com base nessa Escala de Saaty foram atribuídos graus de importância as variáveis através da Comparação Pareada / Recíproca por níveis de hierarquia que resultou na matriz de interação representada na Tabela 3. Nota-se que cada elemento da matriz indica quanto à variável da coluna da esquerda é mais importante em relação a cada fator correspondente a linha superior. Desse modo, quando uma variável e confrontada com ela mesma, um único resultado possível é 1 pelo fato de possuir igual valor de importância.

Tabela 3. Matriz de Comparação Pareada / Recíproca

\begin{tabular}{|c|c|c|c|}
\hline VARIÁVEIS & Declividade & $\begin{array}{c}\text { Taxa de } \\
\text { Impermeabilização }\end{array}$ & Topografia \\
\hline Declividade & 1 & $1 / 3$ & $1 / 6$ \\
\hline Taxa de Impermeabilização & $3 / 1$ & 1 & 1 \\
\hline
\end{tabular}

A partir dos valores ponderados na tabela anterior, foi realizado o cálculo dos Pesos estatísticos para cada variável aplicado a inundação urbana (Tabela 4), obtendo o Índice de Consistência (IC) =0,009174 e a Razão de Consistência (RC) igual a 0,02. Pelo fato do valor da RC ser inferior a 0,10 (ou menor que $10 \%$ ), os pesos estabelecidos para este modelo são aceitáveis segundo Saaty (1977, 2008). Isto é, as comparações realizadas foram coerentes e produziram resultados confiáveis.

Tabela 4. Matriz Normatizada

\begin{tabular}{|c|c|c|c|c|}
\hline VARIÁVEIS & Declividade & $\begin{array}{c}\text { Taxa de } \\
\text { Impermeabilização }\end{array}$ & Topografia & PESO \\
\hline Declividade & 0.1000 & 0.0769 & 0.1111 & $\mathbf{0 . 1 0}$ \\
\hline $\begin{array}{c}\text { Taxa de } \\
\text { Impermeabilização }\end{array}$ & 0.3000 & 0.2308 & 0.2222 & $\mathbf{0 . 2 5}$ \\
\hline Topografia & 0.6000 & 0.6923 & 0.6667 & $\mathbf{0 . 6 5}$ \\
\hline
\end{tabular}

Assim, as variáveis com seus respectivos pesos foram combinadas de maneira a modelar as manchas de inundação expressa no algoritmo matemático, através da ferramenta Raster Calculator $\mathrm{RI}=\mathrm{TO} * 0,65+\mathrm{TI} * 0,25+\mathrm{DC} * 0,10$ sendo: $\mathrm{RI}=$ Risco de Inundação; $\mathrm{TO}=$ Topografia (peso 0,65); $\mathrm{TI}=$ Mapa Taxa de Impermeabilização (peso 0,25); DC = Mapa Declividade (peso 0,10). Na sequência o RI foi extraído para os limites de bairros através do comando Extract by Mask finalizando com a reclassificação em Baixo a Nulo, Médio, Alto e Altíssimo risco. 
Coelho, A. L. N. (2017): "Método de análise hierárquica (AHP) aplicado a inundação urbana após evento de chuva concentrado”, GeoFocus (Artículos), $n^{o}$ 20, p. 183-199. ISSN: 1578-5157 http://dx.doi.org/10.21138/GF.565

\section{Resultados e Discussão}

\subsection{Resultados do Modelo e Validação}

O mapeamento das áreas susceptíveis à inundação é representado na Figura 3, possibilitando visualizar o limite territorial da cidade de Vitória, os limites dos bairros e os locais inundados destacados pelas cores rosa, vermelho e vermelho escuro nas seguintes classes respectivamente: Médio, Alto e Altíssimo Risco, resultantes da avaliação conjunta das variáveis clinografia/declividade, elevação, edificações, eixo de logradouros e afloramentos de rochas com seus respectivos coeficientes, além da incorporação do Processo de Análise Hierárquica (AHP) que atribuiu os pesos de importância, através da álgebra de mapas.

A validação do produto tomou como referência o temporal de 30/10/2014, com o Instituto Nacional de Meteorologia (Inmet, 2014) informando a ocorrência de mais de $100 \mathrm{~mm}$ de chuvas intensas, entre as 15:00h e as 20:00h, registrando uma das maiores precipitações concentradas dos últimos 45 anos. Segundo o Climatempo (2014) e Incaper (2014), a média normal de chuva esperada para todo o mês outubro, na cidade de Vitória, é de aproximadamente $120 \mathrm{~mm}$.

As informações extraídas do jornal (A Tribuna, 2014), evidenciam o fato ocorrido através de registros fotográficos e notícias ao destacar os principais pontos de inundações em 30/10/2014, coincidindo com o modelo gerado no Processo de Análise Hierárquica (Figura 3). A respectiva Figura apresenta também os valores de áreas e os percentuais de inundação dos bairros avaliados revelando que $16 \%$ destes estão classificados entre Médio a Altíssimo risco. 


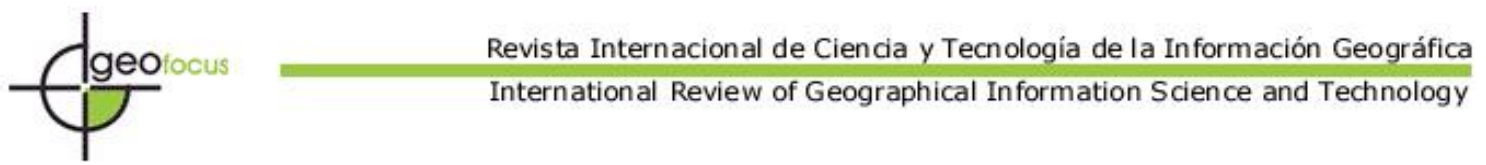

Coelho, A. L. N. (2017): "Método de análise hierárquica (AHP) aplicado a inundação urbana após evento de chuva concentrado", GeoFocus (Artículos), no 20, p. 183-199. ISSN: 1578-5157 http://dx.doi.org/10.21138/GF.565

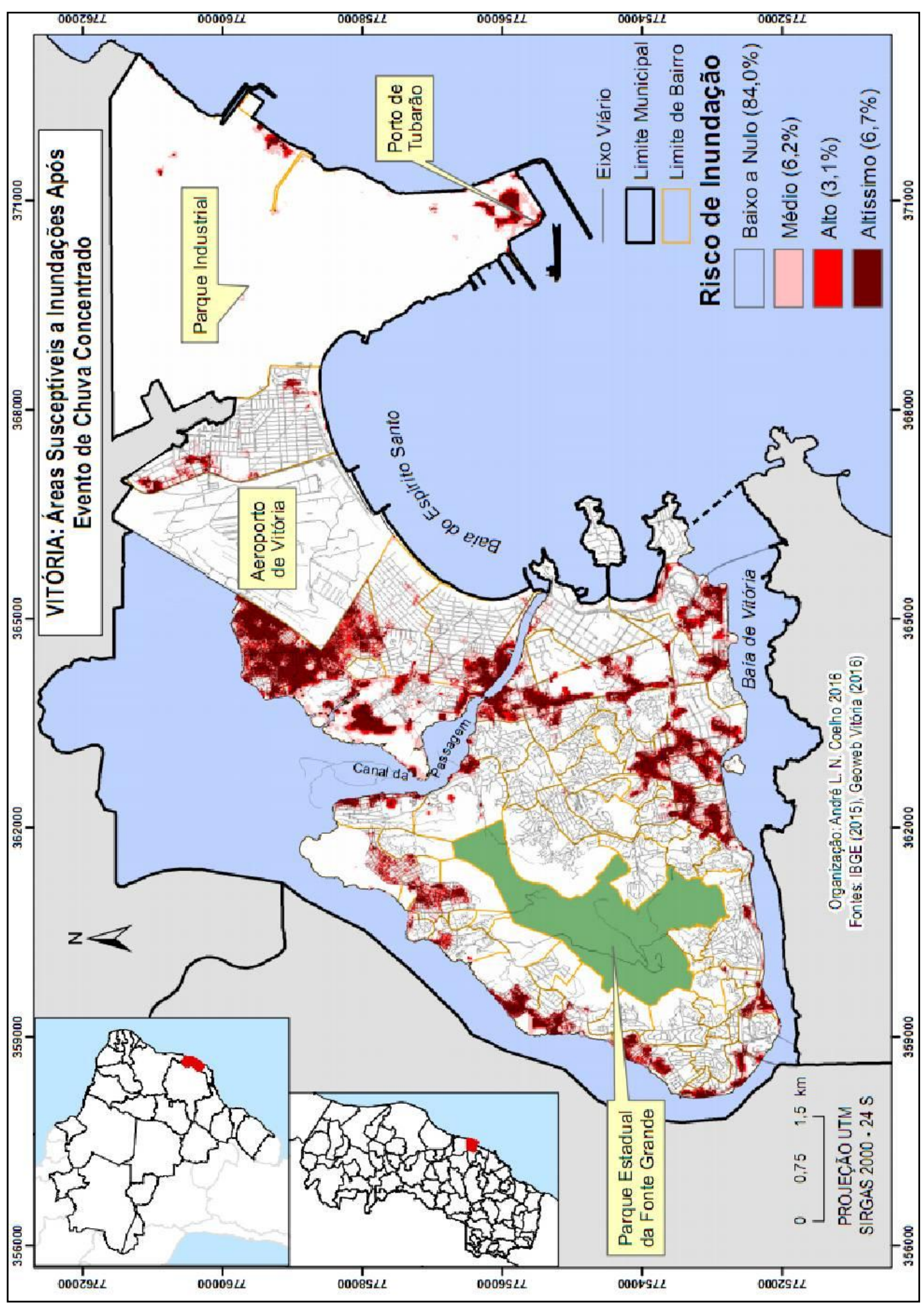

Figura 3. Áreas susceptíveis a inundações em eventos concentrados de precipitação. 
Coelho, A. L. N. (2017): "Método de análise hierárquica (AHP) aplicado a inundação urbana após evento de chuva concentrado", GeoFocus (Artículos), no 20, p. 183-199. ISSN: 1578-5157 http://dx.doi.org/10.21138/GF.565

Além da comprovação em notícias do jornal, o mapeamento de inundação condiz com as áreas alagáveis espacializadas no relatório da Secretaria Municipal de Obras de Vitória - Semob (Figura 4 "B") intitulado: Plano Municipal de Saneamento Básico de Vitória, publicado em Julho de 2015 (Semob/Pmv, 2015).

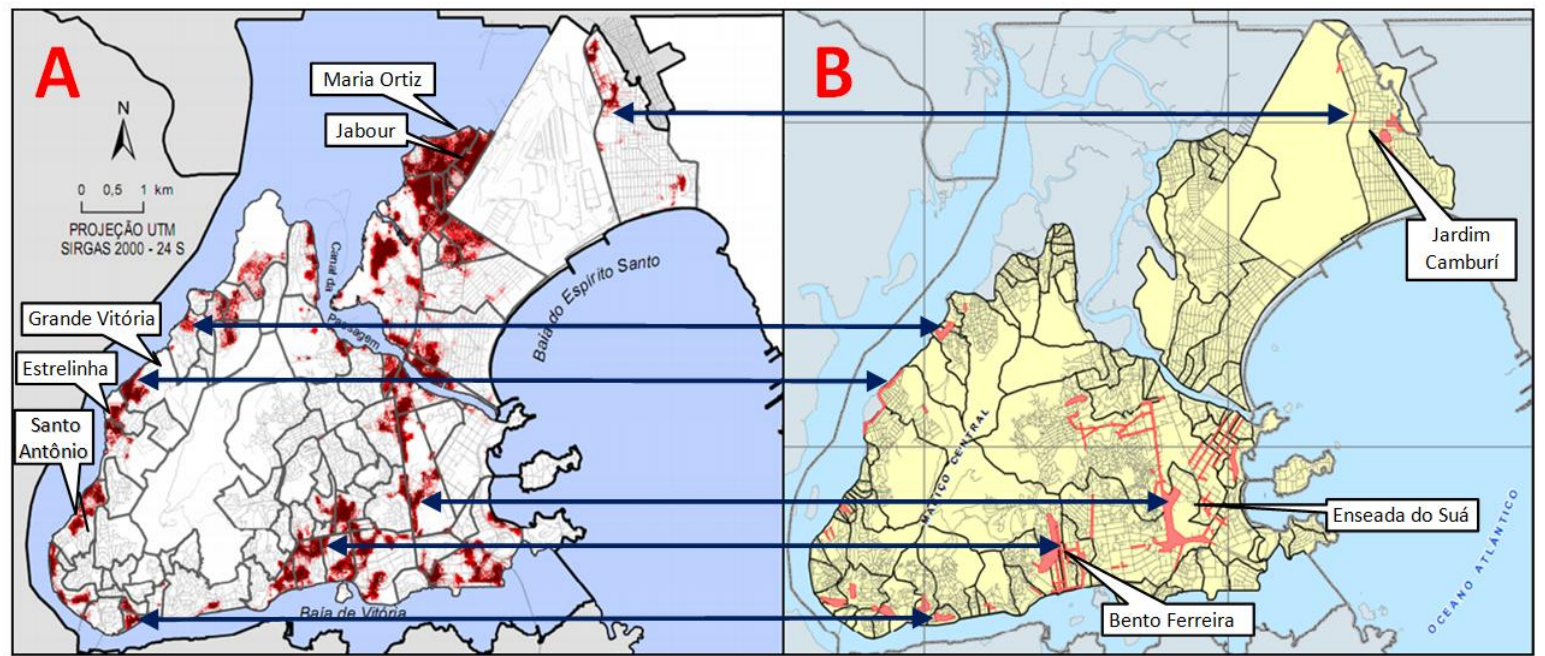

Figura 4. Validação do modelo gerado "A" a esquerda e o mapa de alagamentos "B" a direita da Secretaria Municipal de Obras de Vitória. Em "A" comprovou outras áreas susceptíveis identificadas em campanhas de campo.

Ressalte-se, entretanto, que o mapa modelado (Figuras 3 e 4 "A") apontam outros locais de inundações, a partir da ocorrência de precipitações acima de $100 \mathrm{~mm}$, comprovados em campanhas de campo e em noticiários. Portanto, um produto mais completo e coerente com a realidade do Município.

Já as informações do nível de maré da Diretoria de Hidrografia e Navegação / Centro de Hidrografia Marinha (Dhn/Chm, 2014), no dia do temporal, apontou a elevação de 0,60 m para 1,03 $\mathrm{m}$, entre às 15:00h e às 20:00h, com o pico de 1,07 m às 21:00h no Porto de Vitória. Esse fenômeno de maré alta provavelmente afetou o escoamento das águas pluviais, de determinadas áreas do Município, para baía e mar adjacente resultando na ampliação dos locais e duração das inundações, como por exemplo, no setor oeste da ilha principal (Figuras 3 e 4 "A") em ruas: do Canal (bairro Grande Vitória/Estrelinha); Albuquerque Tovar (bairro Santo Antônio); Reviver, do Penta e TV Oito de Julho (bairro Estrelinha).

\subsection{Bairros Mais Suscetíveis a Inundação}

A Tabela 5 lista, em ordem de percentuais, os 14 bairros da cidade de Vitória que apresentaram mais de $50 \%$ de suas áreas com risco de inundação, entre Médio a Altíssimo, sobressaindo: Antônio Honório e Jabour com mais de $95 \%$ de suas áreas susceptíveis enquanto os bairros Segurança do Lar, Maria Ortiz, Solon Borges e Andorinhas abrangeram mais de $80 \%$ de seus polígonos. 
Coelho, A. L. N. (2017): "Método de análise hierárquica (AHP) aplicado a inundação urbana após evento de chuva concentrado", GeoFocus (Artículos), no 20, p. 183-199. ISSN: 1578-5157 http://dx.doi.org/10.21138/GF.565

\section{Tabela 5 - Percentual por Bairros com mais de 50 \% da Área Sob de Risco de Inundação}

\begin{tabular}{|c|l|c|c|c|}
\hline Ordem & \multicolumn{1}{|c|}{ Bairro } & $\begin{array}{c}\text { Percentual do } \\
\text { Bairro Inundado } \\
(\boldsymbol{\%})\end{array}$ & Área do Bairro (ha) & $\begin{array}{c}\text { Área Inundada do } \\
\text { Bairro (ha) }\end{array}$ \\
\hline 1 & Antônio Honório & 99.4 & 9.43 & 9.37 \\
\hline 2 & Jabour & 95.7 & 19.66 & 18.81 \\
\hline 3 & Segurança do Lar & 89.4 & 6.49 & 5.81 \\
\hline 4 & Maria Ortiz & 89.0 & 55.52 & 49.42 \\
\hline 5 & Solon Borges & 86.1 & 7.19 & 11.50 \\
\hline 6 & Andorinhas & 82.0 & 14.02 & 10.37 \\
\hline 7 & Morada de Camburi & 79.2 & 24.04 & 18.28 \\
\hline 8 & Pontal de Camburi & 76.0 & 34.05 & 25.34 \\
\hline 9 & Republica & 74.4 & 34.39 & 22.18 \\
\hline 10 & Ilha de Santa Maria & 64.5 & 34.34 & 21.31 \\
\hline 11 & Santa Luíza & 62.1 & 12.51 & 7.20 \\
\hline 12 & Santo André & 57.6 & 7.33 & 4.00 \\
\hline 13 & Horto & 54.6 & 30.44 & 15.39 \\
\hline 14 & Consolação & 50.5 & & \\
\hline
\end{tabular}

Organizado pelo autor.

A Figura 5 evidencia, de forma cartográfica a localização dos bairros com mais de $50 \%$ de áreas inundadas destacados na Tabela 5, apontando também, outras classes de percentuais. Nota-se que esses locais estão adjacentes aos corpos d’água como a Baía de Vitória e Canal da Passagem, ou em elevação abaixo ou equivalente ao nível da maré, como o bairro Maria Ortiz.

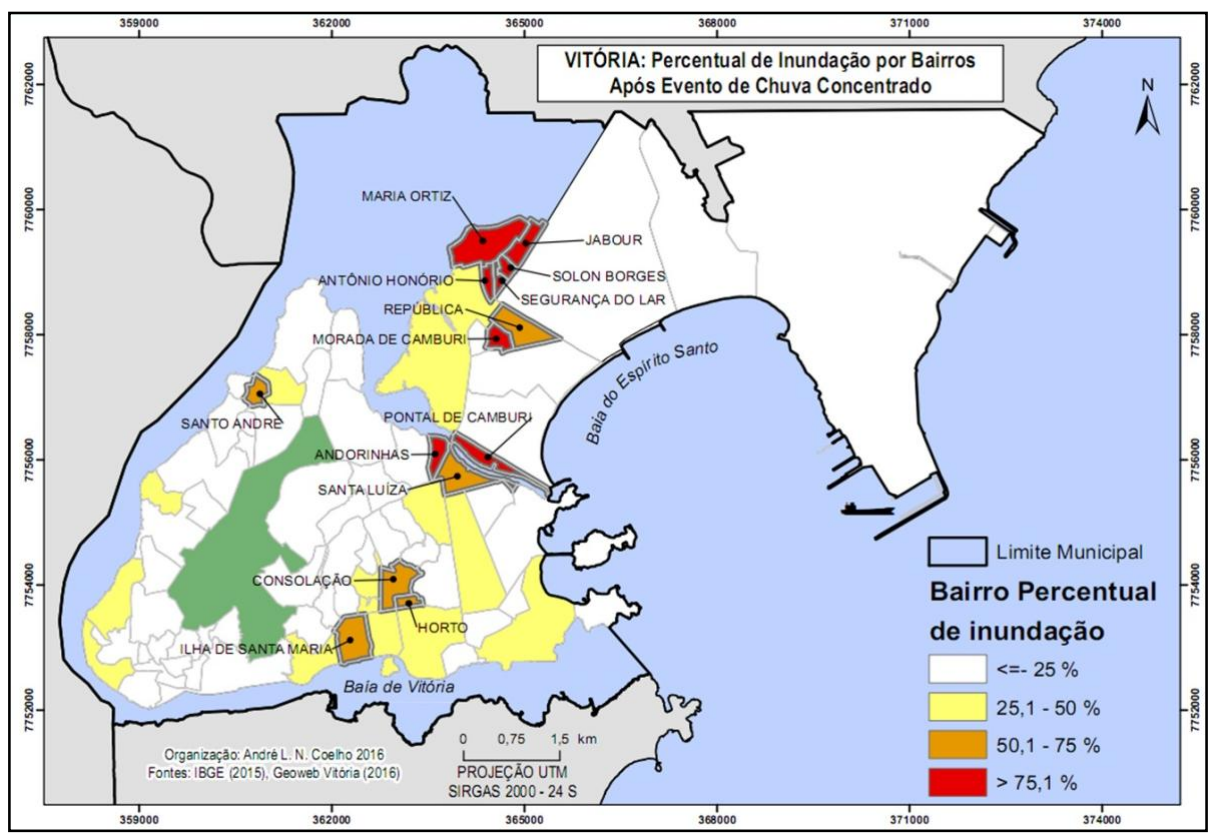

Figura 5. Percentuais de ocorrência de inundação por bairros divididos em 4 classes. 
Coelho, A. L. N. (2017): "Método de análise hierárquica (AHP) aplicado a inundação urbana após evento de chuva concentrado", GeoFocus (Artículos), no 20, p. 183-199. ISSN: 1578-5157 http://dx.doi.org/10.21138/GF.565

Parte considerável desses bairros, como já mencionado, passaram por processos de aterramentos para implantação de novos usos em ambientes antes: alagados, de mar, de manguezais, de topografia irregular como o entalhe dos antigos cordões arenosos e áreas expressivas de restinga suprimida acrescida de nivelamentos do terreno (Coelho, 2017).

Já a Tabela 6 destaca os 18 bairros que apresentaram mais de 15 hectares de suas áreas sob risco de inundação classificados entre Médio e Altíssimo, sobressaindo o Goiabeiras, Parque Industrial e Enseada do Suá que registraram mais de 50 hectares inundados a partir da ocorrência de eventos de temporais superiores a $100 \mathrm{~mm}$.

Tabela 6 - Bairros com risco Médio a Alto de Inundação com Área Superior a 15 hectares.

\begin{tabular}{|c|l|c|c|c|c|}
\hline Ordem & \multicolumn{1}{|c|}{ Bairro } & $\begin{array}{c}\text { Área } \\
\text { Inundada ha }\end{array}$ & $\begin{array}{c}\text { Percentual de } \\
\text { área inundada } \\
\text { no bairro }\end{array}$ & $\begin{array}{c}\text { Área não } \\
\text { inundada } \\
\text { ha }\end{array}$ & Bairro ha \\
\hline 1 & Goiabeiras & 112.04 & 47.5 & 123.77 & 235.81 \\
\hline 2 & Parque Industrial & 56.65 & 3.2 & 1695.11 & 1751.76 \\
\hline 3 & Enseada do Suá & 54.28 & 43.5 & 70.45 & 124.73 \\
\hline 4 & Maria Ortiz & 49.42 & 89.0 & 6.11 & 55.52 \\
\hline 5 & Bento Ferreira & 35.98 & 38.4 & 57.64 & 93.62 \\
\hline 6 & Santa Lúcia & 35.61 & 34.4 & 67.89 & 103.50 \\
\hline 7 & Jardim Camburi & 35.60 & 13.5 & 228.14 & 263.74 \\
\hline 8 & República & 25.34 & 74.4 & 8.72 & 34.05 \\
\hline 9 & Jardim da Penha & 22.81 & 15.6 & 123.84 & 146.65 \\
\hline 10 & Ilha de Santa Maria & 22.18 & 64.5 & 12.21 & 34.39 \\
\hline 11 & Santa Luíza & 21.31 & 62.1 & 13.03 & 34.34 \\
\hline 12 & Santo Antônio & 20.98 & 39.5 & 32.14 & 53.11 \\
\hline 13 & Nova Palestina & 19.01 & 19.0 & 81.00 & 100.01 \\
\hline 14 & Monte Belo & 18.84 & 46.3 & 21.88 & 40.72 \\
\hline 15 & Jabour & 18.81 & 95.7 & 0.85 & 19.66 \\
\hline 16 & Pontal de Camburi & 18.28 & 76.0 & 5.77 & 24.04 \\
\hline 17 & Mário Cypreste & 15.89 & 48.3 & 17.00 & 32.89 \\
\hline 18 & Consolação & 50.5 & 15.06 & 30.44 \\
\hline
\end{tabular}

Organizado pelo autor.

A Figura 6 apresenta o mapa com os 12 bairros que registraram, no modelo gerado, mais de 20 hectares de áreas suscetíveis a inundação, classificados respectivamente nas cores: vermelho (maior que $75 \mathrm{ha}$ ), laranja (50,01 a $75 \mathrm{ha}$ ) e amarelo (20,01 a $50 \mathrm{ha})$. Observa-se, na ilha principal, que 5 dos seis bairros, com mais de 20,01 hectares, estão situados na porção leste, caracterizados em locais em que há um maior contingente populacional, fluxo de pessoas e mercadorias, baixo afastamento entre as construções, elevado índice de superfície impermeável por concreto e asfalto, sendo também, os ambientes em área, que mais foram aterrados. 
Coelho, A. L. N. (2017): "Método de análise hierárquica (AHP) aplicado a inundação urbana após evento de chuva concentrado", GeoFocus (Artículos), no 20, p. 183-199. ISSN: 1578-5157 http://dx.doi.org/10.21138/GF.565

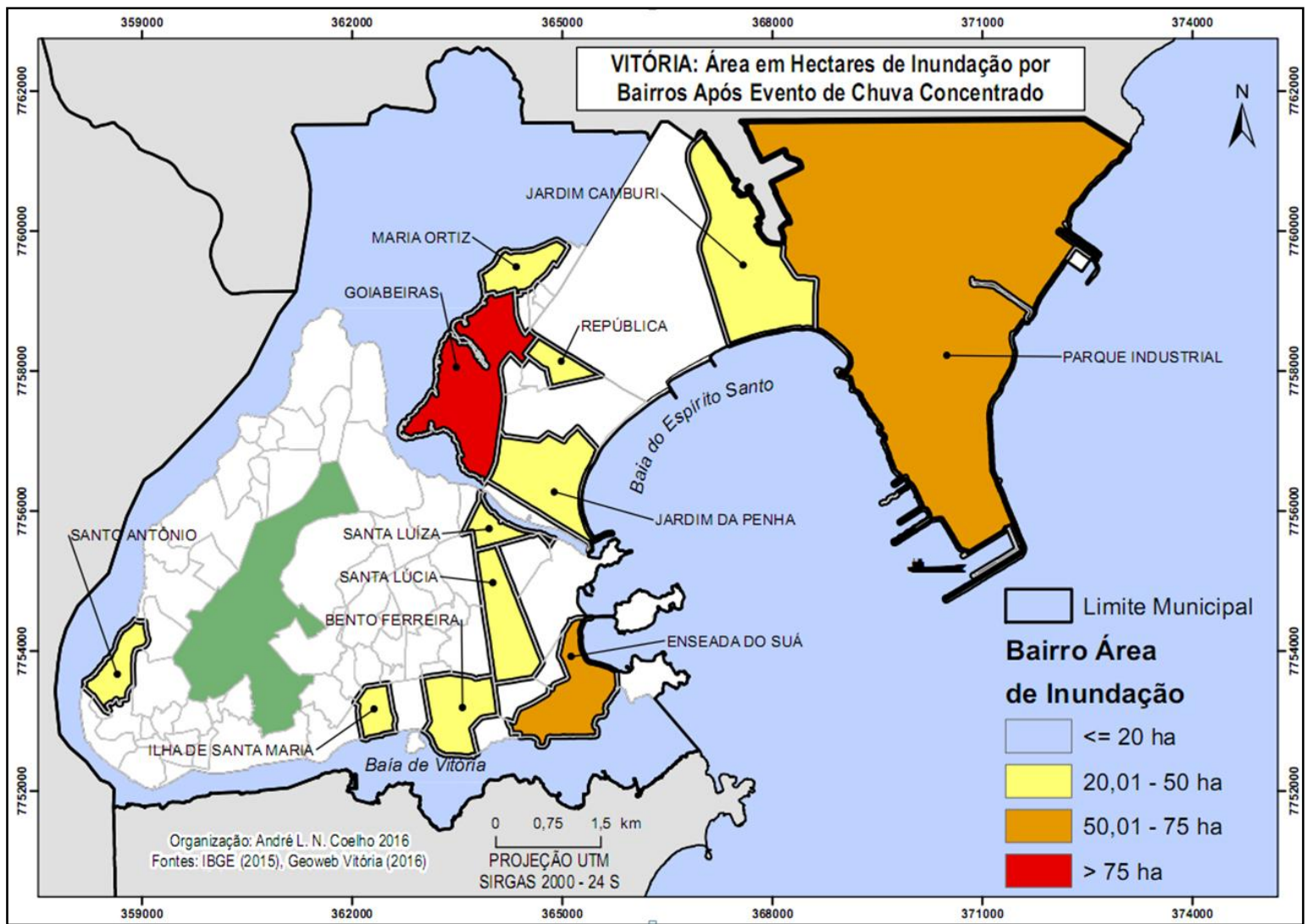

Figura 6. Áreas em hectares inundado por bairros destacando, em vermelho, o Goiabeiras com mais de 75 ha após evento de mais de $100 \mathrm{~mm}$ de precipitação.

Nesse processo de aterramentos, sobressai o setor leste-sudeste na Enseada do Suá, que foi um dos mais transformados ao longo das décadas (Figura 7) resultando na anexação das ilhas: do Boi, do Bode, do Sururu e do Papagaio. Locais que apresentam atualmente elevada taxa de impermeabilização do solo.

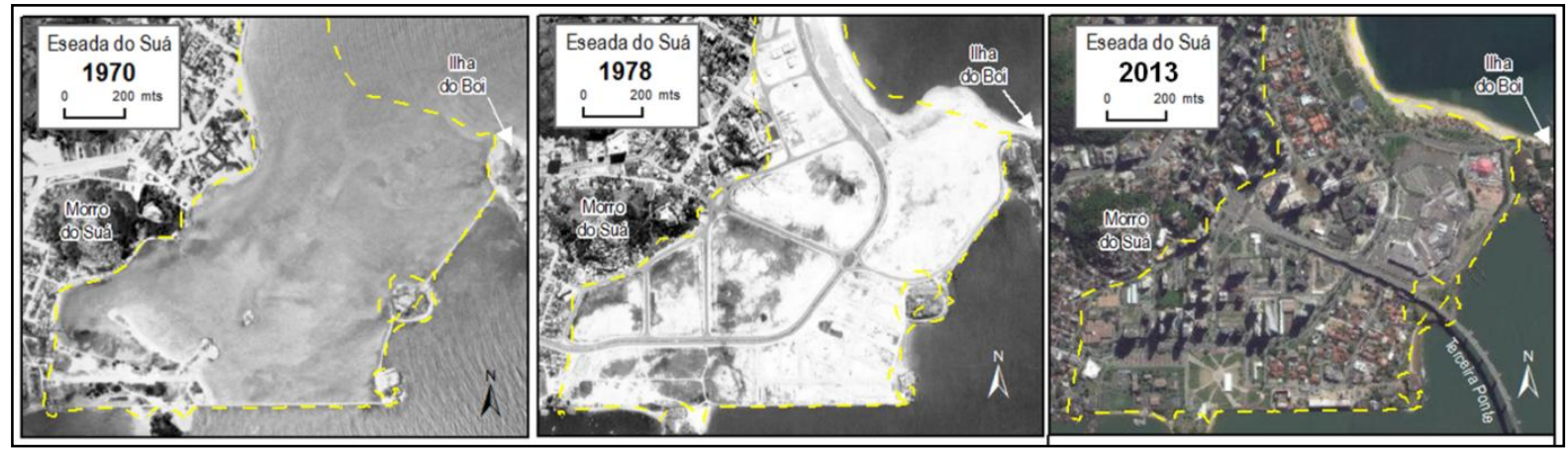

Figura 7 - Etapas de aterro da Enseada do Suá em 1970, 1978 e 2013.

Fonte: Coelho (2017) e Hiparc (2015). 
Coelho, A. L. N. (2017): "Método de análise hierárquica (AHP) aplicado a inundação urbana após evento de chuva concentrado”, GeoFocus (Artículos), no 20, p. 183-199. ISSN: 1578-5157 http://dx.doi.org/10.21138/GF.565

Já na porção continental do Município (Figura 6) é possível identificar que a maioria dos bairros possuem susceptibilidade a inundação, pois parte destes estão situados em um nível topográfico próximo ao nível de maré, como os bairros Goiabeiras, Maria Ortiz e bairro Jardim Camburi, esse ultimo, caracterizado por ruas e passeios estreitos com elevado grau de superfície impermeabilizada

Por meio da espacialização dos pontos de inundação foi possível comprovar que os mesmos estão majoritariamente próximos aos corpos d’água que envolve o Município como a Baía de Vitória, Baía do Espírito Santo e canal da Passagem, com parte desses, localizados em áreas que foram aterradas em nível equivalente e, em alguns casos, abaixo dos valores de marés, favorecendo o acumulo de água durante os eventos de precipitações intensas e marés altas, dificultando o escoamento das águas pluviais para o mar e baía.

\section{Conclusões}

A elaboração do mapa de áreas susceptíveis a inundações na cidade de Vitória possibilitou, a partir do uso de dados vetoriais e matriciais acessíveis e gratuitos, propor um modelo com base no método de Análise Hierárquica de Processos - AHP, identificar, quantificar e classificar os bairros mais propensos a este evento.

A importância desse tipo de aplicação está correlacionada com as políticas municipais e proposição de medidas mitigadoras aos impactos existentes, a exemplo da criação e implantação do Plano Municipal de Saneamento Básico - PMSB, exigido pelas Leis Federais No 11.445/2007 (Política Federal de Saneamento Básico) e a No 12.305/2010 (Política Nacional de Resíduos Sólidos) que estabelecem diretrizes nacionais para o saneamento básico, viabilizando assim, a captação de recursos junto ao Ministério das Cidades para execução de projetos ou obras na área de saneamento.

A partir da elaboração do diagnóstico do PMSB são apontadas ações ou medidas estruturais que modificam o sistema fluvial, evitando prejuízos decorrentes das inundações (Ex.: obras de engenharia: canalização, retificação, extravasadores, canais de inundação, diques, entre outros) e medidas não estruturais em que os prejuízos são reduzidos pela melhor convivência da população com as inundações (Ex.: zoneamento de áreas com risco à inundação; alertas de inundação; implantação de programas de educação ambiental em escolas e comunidades; elaboração de Leis buscando reduzir os eventos de inundações, a exemplo, da regulamentação dessas áreas alagáveis, criação da política municipal saneamento básico, entre outras), hierarquizadas de acordo com os recursos a serem investidos no curto, médio e longo prazo.

Nesse sentido, o presente trabalho pode contribuir com a elaboração/revisão do Plano Municipal de Saneamento Básico - PMSB, na etapa de diagnóstico, ao apontar as áreas mais susceptíveis a inundações, pois o mesmo considerou as peculiaridades e particularidades naturais da cidade durante os eventos de temporais.

\section{Referências Bibliográficas}


Coelho, A. L. N. (2017): "Método de análise hierárquica (AHP) aplicado a inundação urbana após evento de chuva concentrado”, GeoFocus (Artículos), no 20, p. 183-199. ISSN: 1578-5157 http://dx.doi.org/10.21138/GF.565

Carneiro, Paulo Roberto Ferreira; Miguez, Marcelo Gomes. Controle de Inundações Em Bacias Hidrográficas Metropolitanas. Editora: Annablume. São Paulo, 302p. 2011.

Castro, A. L. C. Glossário de defesa civil: estudos de riscos e medicina de desastres. Brasília: Sedec. 2005.

Chin, Anne. Urban Transformation of River Landscapes in a Global Context. Geomorphology, 79, pp. 460-487. 2006.

Chuva Recorde. A Tribuna. Vitória, ES, 31 de outubro de 2014. Reportagem Especial - nº 25.065. 2014, Edição de 92 páginas.

Climatempo. Noticias por Josélia Pegorim. O que causou o temporal que alagou Vitória (ES)?, 30/10/2014. [Acesso em 03/04/2015]. Disponível http://www.climatempo.com.br/noticias/268591/o-que-causou-o-temporal-que-alagou-vitoria-es/. (2014).

Coelho, André L. N. Geotecnologias aplicadas na distribuição espacial dos aterros da cidade de Vitória / ES - Caderno de Geografia, v.27, n.51, PP. 760 - 775, 2017.

Cunha, Sandra. B. Rios Desnaturalizados. In: BARBOSA, J. L. (Org.). Ordenamento Territorial e Ambiental. 1. ed. Niterói: Eduff, pp. 171-191. 2012.

Cunha, B. Canais Fluviais e a Questão Ambiental. In: Cunha, S. B. \& Guerra, A. J. T. (orgs.) A Questão Ambiental: diferentes abordagens. RJ, Bertrand Brasil, pp. 219-238. 2003.

Dhn/Chm - Diretoria de Hidrografia e Navegação/Centro de hidrografia da Marinha. Previsões de marés (máximas e mínimas diárias). [Acesso em 01/12/2014]. http://www.mar.mil.br/dhn/chm/boxprevisao-mare/tabuas/. (2014).

Em-Dat. The International Disaster Database. Centre for Research on the Epidemiology of Disasters - Cred. [Acesso em: 06/10/2016]. Disponível em: http://www.emdat.be/disaster_trends/index.html 2015.

Gregory, K. J. The Human Role in Changing River Channels. Geomorphology. Volume 79, 15 September, Pages 172-191. 2006.

Ibge - Instituto Brasileiro de Geografia e Estatística. Estimativas da população 2017. [Acesso em 16/10/2017].

http://www.ibge.gov.br/home/estatistica/populacao/estimativa2017/estimativa_dou.shtm (2017).

Ibge - Instituto Brasileiro de Geografia e Estatística Mapas Interativos do IBGE: Base de Dados Geográficos. [Acesso em 04/03/2015]. ftp://geoftp.ibge.gov.br/. (2015).

Ibge - Instituto Brasileiro de Geografia e Estatística. Mapa de unidades climáticas do Brasil. [Acesso em 12/03/2015]. http://www.ibge.gov.br/home/geociencias/cartogramas/clima.html. (2010).

Ibge - Instituto Brasileiro de Geografia e Estatística. Resolução IBGE $n^{o}$ 1/2005 que altera a caracterização do referencial geodésico brasileiro. [Acesso em 03/09/2015]. ftp://geoftp.ibge.gov.br/documentos/geodesia/projeto_mudanca_referencial_geodesico/legislacao/rp r_01_25fev2005.pdf. (2005). 
Coelho, A. L. N. (2017): "Método de análise hierárquica (AHP) aplicado a inundação urbana após evento de chuva concentrado", GeoFocus (Artículos), no 20, p. 183-199. ISSN: 1578-5157 http://dx.doi.org/10.21138/GF.565

Ibge - Instituto Brasileiro de Geografia e Estatística. Carta Topográfica SF-24-V-B-1, 1:50.000. (1980).

Ijsn/Cgeo - Instituto Jones dos Santos Neves / Coordenação de Geoprocessamento. Base de Dados Geográficos. [Acesso em: 06/05/2015]. http://www.ijsn.es.gov.br/ (2013).

Ijsn/Cgeo - Instituto Jones dos Santos Neves / Coordenação de Geoprocessamento. Ortofotomosaico vôo ano 2014 - Município de Vitória. Padrão PEC “A” (2014).

Incaper - Instituto Capixaba de Pesquisa, Assistência Técnica e Extensão Rural. Dados e Informações referentes as intensas chuvas em 30/10/2014. (2014).

Inmet - Instituto Nacional de Meteorologia. Banco de Dados Meteorológico para Ensino e Pesquisa. [Acesso em: 04/12/2014]. http://www.inmet.gov.br/projetos/rede/pesquisa/inicio.php. (2014).

Hiparc Geotecnologia 2015. Veracidade: linha do tempo 1970 - 1978. [Acesso em: 5/11/2016]. Disponível em: http://www.veracidade.com.br/.

Jensen, John R. Sensoriamento Remoto do Ambiente: uma perspectiva em recursos terrestres, São José dos Campos, SP: Parêntese. 2009.

Menezes, P. L.; Fernandes, M. C. Roteiro de Cartografia. SP: Oficina de Textos. 2013.

Mendonça, F. de A., Danni-Oliveria, I. M. Climatologia: noções básicas e climas do Brasil. São Paulo. Editora Oficina de texto. 206p. 2007.

Pmv/Geoweb - Prefeitura Municipal de Vitória. GeoWeb Vitória: Base de Dados Geográficos. [Acesso em: 5/03/2015]. http://geoweb.vitoria.es.gov.br/. (2015).

Radambrasil. Levantamento de Recursos Naturais. Geologia, Geomorfologia, Solos, Vegetação e Uso Potencial da Terra. v. 32, Folhas SF 23/24 Rio de Janeiro / Vitória. Rio de Janeiro: IBGE/Ministério das minas e energia - Secretaria Geral. 775 p. 1983.

Saaty, Thomas L. Decision making with the analytic hierarchy process. Int. J. Services Sciences, Vol. 1, 2008.

Saaty, Thomas L. A scaling method for priorities in hierarchical structures. Journal of Mathematical Psychology, v. 15, p. 234-281, 1977.

Sausen, Tania M.; Narvaes, Igor da S. Sensoriamento Remoto Para Inundação e Enxugada. In: Sausen, Tania M.; Lacruz, Maria S. P. Sensoriamento Remoto Para Desastres. São Paulo: Oficina de Textos, pp. 118 - 147. 2015.

Semob/Pmv - Secretaria Municipal de Obras / Prefeitura Municipal de Vitória. Plano Municipal de Saneamento Básico de Vitória - ES: (PMSB) Relatório do Produto 2: diagnóstico da situação da prestação dos serviços de saneamento básico - julho/2015. [Acesso em 22/11/2015]. http://hotsites.vitoria.es.gov.br/pmsb/wp-content/uploads/2015/08/produto-02_a1.pdf. (2015).

Slocum, Terry A.; Mcmaster, Robert B; Kessler, Fritz C.; Howard, Hugh H. Thematic Cartography and Geovisualization, 3rd Edition, Ph. Series in Geographic Information Science, Hardcover. 2008.

Tucci, Carlos. E. M. Hidrologia: ciência e aplicação. Porto Alegre: Editora da Universidade, $4^{\circ}$ Ed. 943p. 2009. 
Coelho, A. L. N. (2017): "Método de análise hierárquica (AHP) aplicado a inundação urbana após evento de chuva concentrado”, GeoFocus (Artículos), $n^{o}$ 20, p. 183-199. ISSN: 1578-5157 http://dx.doi.org/10.21138/GF.565

Tucci, Carlos E. M.; Bertoni Juan Carlos. Inundações Urbanas na América do Sul. Porto Alegre: Associação Brasileira de Recursos Hídricos. 2003.

Usgs - Geological Survey / Serviço Geológico Americano Aquisição. Dados de Altitude Aster/Gdem - Advanced Spaceborne Thermal Emission and Reflection Radiometer / Global Digital Elevation Model. [Acesso em 22/11/2015]. http://earthexplorer.usgs.gov. (2011).

Varejao-Silva, M. A. Metereologia e climatologia. Recife. 2005. 
